\title{
Evaluation of radiation protection conditions in intraoral radiology
}

\author{
Cristiano Miguel*, Frieda Saicla Barros, Anna Silvia Penteado Setti da Rocha, \\ João Gilberto Tilly Junior, Cláudio Domingues de Almeida
}

\begin{abstract}
Introduction: The dental radiology represents about $20 \%$ of human exposure to radiation in radio diagnostic. Although the doses practiced in intraoral dentistry are considered low, they should not be ignored due to the volume of the performed procedures. This study presents the radiation protection conditions for intraoral radiology in Curitiba - PR. Methods: Data was collected through a quantitative field research of a descriptive nature during the period between September of 2013 and December of 2014. The survey sample consisted of 97 dentists and 130 intraoral equipments. The data related to the equipments was collected using structured questions and quality control evaluations. The evaluations of the entrance skin dose, the size of the radiation field and the total filtration were performed with dosimetry kits provided and evaluated by IRD/CNEN. The exposure time and voltage were measured using noninvasive detectors. The occupational dose was verified by thermoluminescent dosimeters. The existence of personal protection equipment, the type of image processing and knowledge of dentists about radiation protection were verified through the application of a questionnaire. Results: Among the survey's results, it is important to emphasize that $90 \%$ of the evaluated equipments do not meet all the requirements of the Brazilian radiation protection standards. Conclusion: The lack of knowledge about radiation protection, the poor operating conditions of the equipments, and the image processing through visual method are mainly responsible for the unnecessary exposure of patients to ionizing radiation.
\end{abstract}

Keywords: Intraoral radiology, Quality control in radiology, Radiation protection.

\section{Introduction}

The equipments and techniques used in radiology are constantly evolving and several methods of image diagnosis are used. However, in dentistry, radiography is considered as the primary means to get a clinical diagnosis. Consequently, a large number of patients require radiographic exams (Alcaraz et al., 2012).

Studies presented in 2008 pointed out that according to the survey conducted from 1996 to 2007 , the total number of medical and dental radio diagnostic exams performed worldwide every year is estimated between 2.4 and 3.6 billion (United..., 2010).

In addition to the exposure of patients, there is the occupational exposure, characterized by people who are exposed to radiation during labor activity. The occupational dose has decreased with the evolution of the technology used in radiological equipments and the greater care with radiological protection. However, low doses of radiation, as practiced in intraoral dental radiology, may cause damage to living organisms. The estimated risk of induction of fatal cancer or serious hereditary ill-health from intraoral radiography is approximately 1 in every 10 million (Abbott, 2000).
In order to allow radiology services to reach a standard of quality and safety for the population, patients and healthcare professionals, the Brazilian Ministry of Health Ordinance 453/1998 (Brasil, 1998) requires the implementation of a quality assurance program, and that periodic tests of quality control be performed in radiological equipments through calibrated equipments. According to the standard, the processing of radiographies in dental offices can be accomplished through manual processing portable chambers, and this method is widely used among dentists because of its convenience and low cost. However the revelation chambers should prevent the entry of light from the lighting at dental offices in order to avoid the presence of veiling glare, a relevant factor in the quest for image quality. Two types of manual processing of radiographies can be performed in dental offices. The first is the inspectional or visual mode, where the film is placed in a developing solution and from time to time, the appearance of the image is examined. The second is the method of time and temperature. By using this method, is possible to utilize a table with fixed times for each step. 
In order to analyze the radiation protection conditions in dental offices in the city of Curitiba - PR, a quality control evaluation of intraoral X-ray equipments was carried out, one questionnaire was applied on radioprotection, and the occupational dose of dentists was evaluated. Through the proposed methods, it was possible to identify the poor operating conditions of the equipments and the lack of dentists' knowledge regarding the radiation protection.

\section{Methods}

Data was collected in the city of Curitiba - PR, with the use of structured questions filled by the researcher and the dentists, and the evaluation of intraoral X-ray equipments. Thermoluminescent dosimeters (TLDs) were provided to 44 dentists of the sample, in order to evaluate the occupational dose in dental offices. The weekly workload of dental offices was calculated using Equation 1. The data was used to evaluate the need for the use of personal monitoring and protective barriers.

$\mathrm{W}=\mathrm{mA}^{\star} \min ^{\star} \mathrm{N} /$ week

Where:

$\mathrm{mA}$ : electric current in $\mathrm{mA}$;

min: exposure time in minute;

N/week: number of exams performed per week.

Knowledge about the standards of radiation protection, equipment characteristics, work procedures and image processing were obtained through a questionnaire composed of 12 questions.

The revelation chambers were tested to ensure that they were fully sealed from light. The test consisted of removing a film from its protective cover inside the revelation chamber and leaving a coin on the film for one minute before processing it chemically. After the revelation, if it is not possible to observe the image of the coin, as is shown in the image 1 of Figure 1, the chamber is considered compatible. When the image is perceptible, as shown in image 2 , it leads to the conclusion that the revelation chamber was not totally sealed against the entrance of light, and the chamber was considered not compatible.

To check if the equipment has a dead man type of trigger, a shot has to be made with an exposure time of about 1 second. During the shot, it is necessary to stop pressing the trigger. If the shooting is interrupted; this means that the trigger is of a dead man type, if the shooting continues even without any pressure to the device, the trigger is not of the recommended type.

The quality control evaluations performed on the equipments during the research were: checking of the entrance skin dose of patients in intraoral radiography exams of a molar tooth, the full equipment filtration calculation, evaluation of the size of the radiation field, evaluation of the voltage accuracy and reproducibility, evaluation of accuracy and reproducibility of exposure time, measure of the distance from the focus to the end of the locator, measure of the size of the shutter cable, verification of the type of control system used for the exposure time, and the radiation trigger based control system.

The acquisition of data used to evaluate the entrance skin dose, filtration and size of the radiation field was done through the IRD dosimetry kit program. The dosimetry kit is a high-impact polyethylene black and opaque box, measuring $8.5 \times 12.0 \times 1.0 \mathrm{~cm}$ and

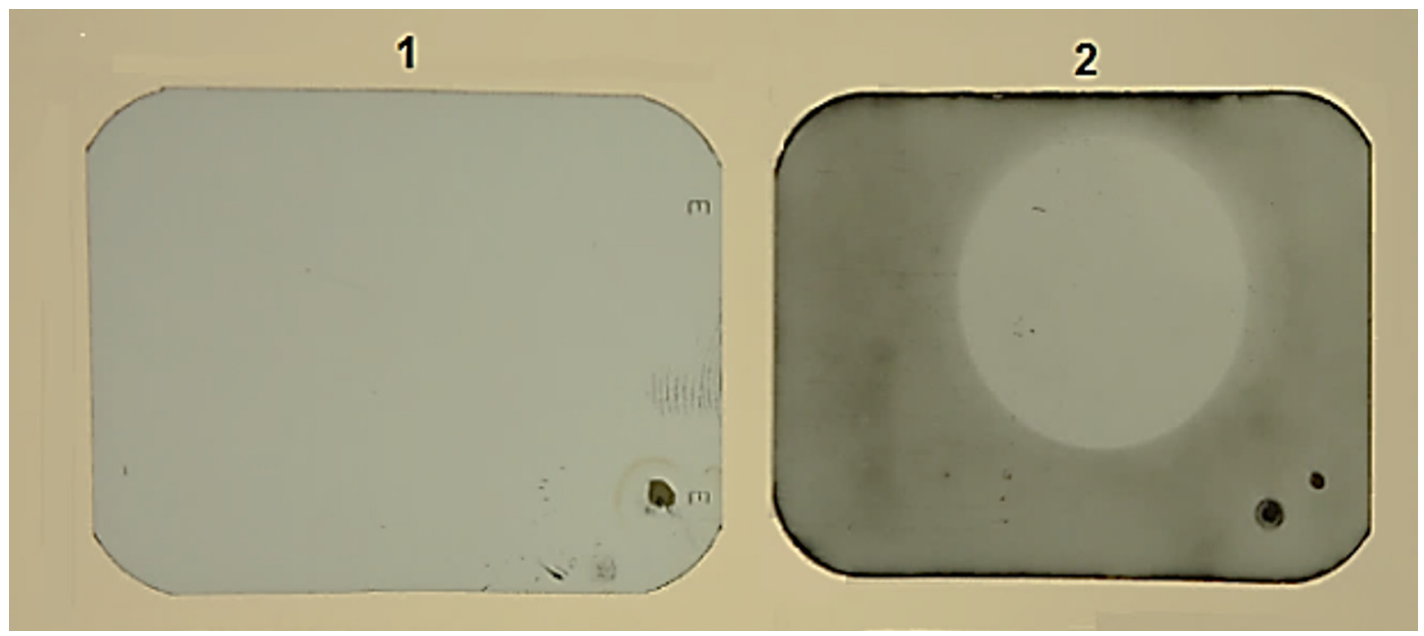

Figure 1. Tests with revelation chambers. Picture 1: Result indicates chamber as compatible; Picture 2: shadow of a testing coin indicates that the chamber was not totally sealed - not compatible. 
containing a removable inner tray. The upper face of the box has a central black circle and the indication of the location for the exposure. The underside displays instructions on the appropriate way to make the irradiation. Internally, the upper face of the tray contains two circular cavities coupled with a pair of thermoluminescent dosimeters. The same occurs with the bottom surface, where the cavities are positioned transversely to the cavities of the upper surface. In the middle of the tray, between the cavities, there is an aluminum filter with $3.5 \mathrm{~cm}$ in diameter and $3.0 \mathrm{~mm}$ thickness. The upper surface of the tray contains an area for the insertion of a radiographic film used to evaluate the size of the radiation field.

At the time of the experiment, the tube head of each equipment was positioned with the end of the locator facing up to avoid interaction of a scattered radiation with the test object. The kit was positioned and fixed with adhesive tape in contact with the end of the X-ray equipment locator, and irradiated with the exposure parameters used to perform the radiography of an upper molar tooth for an average adult patient. The exposure parameters used were provided by the dentists responsible for the equipment. The results of the evaluations of the dosimetry kit were provided by the Institute of Radiation Protection and Dosimetry (IRD) of the National Nuclear Energy Commission through quality control reports for all equipments. Figure 2 shows the experiment during the acquisition of data through the dosimetry kit.

The acquisition of data to evaluate the voltage accuracy and reproducibility was performed through a $\mathrm{kVp}$ meter of Electronic Control Concepts brand, model 815 , and serial number 310 . In all of the evaluated equipments, a series of 4 exhibits was done in the center of the measuring instrument. The adopted

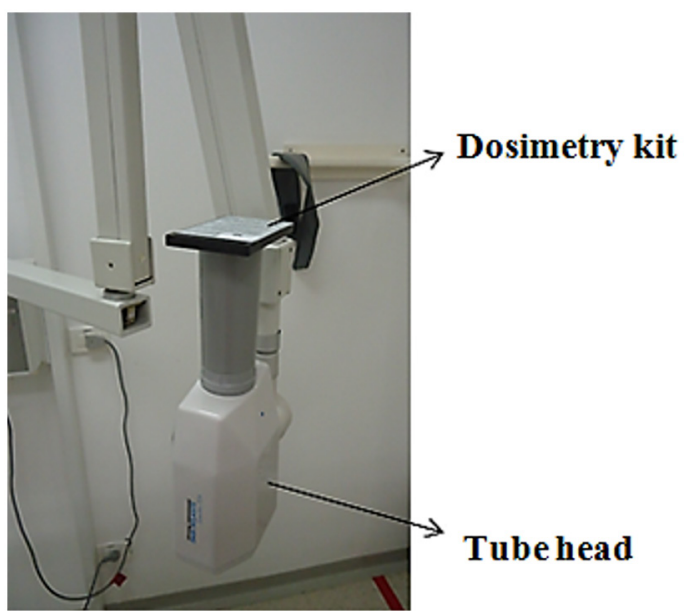

Figure 2. Dosimetry kit iradiation experiment. compliance parameter to evaluate the variation of voltage accuracy and reproducibility was the one described in the Ordinance 453/98 (Brasil, 1998). The standard determines that the deviation must be less than or equal to $\pm 10 \%$.

To evaluate the exposure time, 4 exposures in 4 exposure time slots were done, mostly used by each dentist through the X-rays digital timer MRA from the Industry Electronic Equipment Ltda. Brand, serial number 03-126. The adopted compliance parameter to evaluate the variation of accuracy and reproducibility of the exposure time was the one described in the Ordinance 453/98 (Brasil, 1998). The standard determines that the deviation must be less than or equal to $10 \%$.

The evaluation of the locator cone length was performed with a measuring tape, considering the distance from the extremity of the locator to the mark on the head that represents the focal point of the equipment. The locators were considered in compliance when they showed a cone length of at least $18 \mathrm{~cm}$ for equipments with voltage up to $60 \mathrm{kVp}$, at least $20 \mathrm{~cm}$ for equipments with tube voltage from 60 to $70 \mathrm{kVp}$, and at least $24 \mathrm{~cm}$ for equipments with tube voltage higher than $70 \mathrm{kVp}$.

The measuring of the shutter cable length was performed with a measuring tape, stretching the shutter cable to its limit. The adopted compliance parameter for the shutter cable length was the described in the Ordinance 453/98 (Brasil, 1998). The Ordinance stipulates that the minimum length must be 2 meters.

The type of the timers (mechanical or electronic) was visually verified. Only the electronic ones were considered in conformity.

In order to be considered in accordance, the shooting system must be manual and with a dead man switch, that is, it must be possible for the operator to interrupt the exposure at any time. The evaluation was performed by the visual checking of the existence of an automatic firing system and a test exposure.

The evaluation of the occupational dose of dentists was performed through individual usage dosimeters (TLDs) provided to 44 randomly chosen dentists of the sample, who used them for 30 days.

The week workload of each dental office was calculated by Equation 1. If the workload is greater than $4 \mathrm{~mA} . \mathrm{min} /$ week, the use of a personal dosimeter becomes mandatory. For workload exceeding $30 \mathrm{~mA}$. $\mathrm{min} /$ week, in addition to the use of the dosimeter, the operator should remain behind a protective barrier with a minimum thickness of $0.5 \mathrm{~mm}$ lead equivalent.

The statistical analysis of the collected data was performed using the statistical software Minitab. 


\section{Results}

Table 1 shows the results of the quality control measures.

The result of the general evaluation of the quality control of the equipment demonstrated that $10 \%$ were in accordance with the Brazilian regulations. When analyzing the equipment considered in accordance in all evaluations, $85 \%$ of the equipments had nominal voltage of $70 \mathrm{kVp}$; the remaining $15 \%$ had nominal voltage from 60 to $66 \mathrm{kVp}$. No equipment with a nominal voltage of $50 \mathrm{kVp}$ was considered in compliance.

All of the sample equipments operated with fixed voltage, were single phase and self-rectified. The equipments with nominal voltage of $70 \mathrm{kVp}$ represented $62 \%$ of the sample, the equipments with $50 \mathrm{kVp}$ represented $19 \%$, the equipments with $60 \mathrm{kVp}$ were responsible for $15 \%$, and the equipments of 66 and $65 \mathrm{kVp}$ together made up $4 \%$ of the sample. However this distribution of nominal voltage was changed when compared to the distribution of the voltage measured. According to the voltage measures, the equipments with voltage bigger than $70 \mathrm{kVp}$ represented $2 \%$ of the sample, the equipments with voltage between 60 and $70 \mathrm{kVp}$ represented $58 \%$, the equipments with voltage between 50 and $60 \mathrm{kVp}$ represented $21 \%$, and the equipments with voltage less than $50 \mathrm{kVp}$ were responsible for $19 \%$ of the equipment sample.

The evaluation of exposure times that were considered non-compliant identified that $73 \%$ of the time slots were between 0.1 and 0.69 seconds. However, the average exposure time used by dentists was 0.84 seconds.

The evaluation of the occupational exposure of dentists, through the effective doses measured in all dosimeters (TLDs), was considered as BG, i.e., dose lower than the record level (0.2 milisievert) for all evaluations. It was possible to identify that during the exposure of patients to X-rays, $23 \%$ of dentists positioned themselves inside the exam room and visualized the patients, $36 \%$ were outside the room and visualized the patients, $40 \%$ were outside the room and did not visualize the patients, and $1 \%$ were inside the exam room and did not visualize the patients.

It was verified, through the workload calculation of dental offices, that $15.4 \%$ of dentists should make use of monitoring through dosimeter, because they work with workload greater than $4 \mathrm{mAmin} /$ week.

Table 2 shows the results of the questionnaire on radiation protection responded by the dentists.

Through calculation of the confidence interval of the equipment conformity, it is possible to estimate with $95 \%$ confidence that, in Curitiba, the percentage of equipment in compliance is within the range of $5.4 \%$ and $16.5 \%$.
Table 1. Results of the quality control evaluations.

\begin{tabular}{lcc}
\hline \multicolumn{1}{c}{ measure } & $\begin{array}{c}\text { In accordance } \\
\mathbf{( \% )}\end{array}$ & $\begin{array}{c}\text { Not in } \\
\text { accordance } \\
(\mathbf{\%})\end{array}$ \\
\hline Entrance skin dose & 84.5 & 15.5 \\
Total filtration & 83.7 & 16.3 \\
Size of the radiation field & 83.7 & 16.3 \\
Voltage accuracy & 55.0 & 45.0 \\
Voltage reproducibility & 100.0 & 0.0 \\
Exposure time accuracy & 27.0 & 73.0 \\
Exposure time & 73.0 & 27.0 \\
reproducibility & & 6.9 \\
Locator cone length and & 93.1 & 3.1 \\
type & & 33.1 \\
Shutter cable length & 96.9 & 3.8 \\
X-ray shutter system type & 66.9 & \\
Exposure time control & 96.2 & 90.0 \\
device type & & \\
General evaluation of & 10.0 & \\
equipments & & \\
\hline
\end{tabular}

Table 2. Results of the questionnaire on radiation protection.

\begin{tabular}{|c|c|c|}
\hline Questions & Yes $(\%)$ & No $(\%)$ \\
\hline $\begin{array}{l}\text { Is there a lead apron at the } \\
\text { installation? }\end{array}$ & 85 & 15 \\
\hline $\begin{array}{l}\text { Is there a thyroid collar at the } \\
\text { installation? }\end{array}$ & 68 & 32 \\
\hline $\begin{array}{l}\text { Are the X-ray examinations } \\
\text { performed with positioners? }\end{array}$ & 66 & 34 \\
\hline $\begin{array}{l}\text { Is the X-ray trigger system of a } \\
\text { dead man type? }\end{array}$ & 69 & 31 \\
\hline $\begin{array}{l}\text { Are the radiographies processed } \\
\text { by the visual method? }\end{array}$ & 72 & 28 \\
\hline $\begin{array}{l}\text { Are the radiographies processed in } \\
\text { portable revelation boxes? }\end{array}$ & 82 & 18 \\
\hline $\begin{array}{l}\text { Does the revelation box properly } \\
\text { avoid the entry of light? }\end{array}$ & 34 & 66 \\
\hline $\begin{array}{l}\text { Does the image processing } \\
\text { procedure include thermometer } \\
\text { and the method of time/ } \\
\text { temperature? }\end{array}$ & 16 & 84 \\
\hline $\begin{array}{l}\text { Is the Ordinance } 453 / 98 \mathrm{MH} \\
\text { known by the dentists? }\end{array}$ & 63 & 37 \\
\hline $\begin{array}{l}\text { Is there a copy of the Ordinance } \\
453 / 98 \mathrm{MH} \text { at the installation? }\end{array}$ & 13 & 87 \\
\hline $\begin{array}{l}\text { Has the dentist who operates } \\
\text { the equipment already done the } \\
\text { radiation protection course? }\end{array}$ & 37 & 63 \\
\hline $\begin{array}{l}\text { If the dentist has not participated } \\
\text { in radiation protection courses, } \\
\text { is there interest in participating } \\
\text { in one? }\end{array}$ & 71 & 29 \\
\hline
\end{tabular}

\section{Discussion}

It has been determined that $90 \%$ of the intraoral equipments were not totally in accordance with the radiation protection recommendations. Nevertheless 
$84,5 \%$ of the entrance skin dose measurements was considered in conformity. This result may be due to factors that it does not directly interfere with the evaluation of the entrance skin dose through simulation, such as the type of X-ray trigger, shutter cable size and the high rate of non-compliance of exposure times in the lower ranges. The main reason for the low performance of the equipment with regard to voltage is the fact that they are all self-rectified, that is, they have no rectifier circuit of voltage, are single-phased with waveform equal to the half-wave rectification (Bushong, 2010). The ordinance 453 (Brasil, 1998) prohibits the use of self-rectified system in conventional radiology. According to Tilly (2010), these equipments waste $50 \%$ of the consumed energy and the result is the low yield for the production of $\mathrm{X}$-rays. The measuring of the entrance skin dose is intended to verify if the exposure of patients is within the reference levels stipulated for intraoral exams. The reference value for the entrance skin dose in Brazil is $3.5 \mathrm{mGy}$, whereas the Spanish Protocol and the European Guide recommends that the patient's exposure shall be less than $4.0 \mathrm{mGy}$. The average of the entrance skin dose calculated in the evaluations performed in Curitiba - PR was $2.34 \mathrm{mGy}$, below the reference value recommended by the Ordinance No. 453. The entrance skin dose of patients should be optimized by adapting the $\mathrm{X}$-ray equipment to the current radiation protection standards, reducing the exposure time and implementing image processing through time-temperature methodology.

The primary means of patient protection used in dental offices is the lead apron, although the use of thyroid protectors is neglected. Gomes et al. (2012) interviewed patients exposed to intraoral x-ray and identified that the lead apron is always given to $61 \%$ of patients, and only $24.7 \%$ of patients are routinely protected by thyroid protectors. The work done by Bonzoumet (2006) on the evaluation of the exposure around the eyes and the neck regions in intraoral exams shows that the use of a thyroid protector and a positioner at the exposure time provides a significant reduction in the radiation dose that reaches the region of the crystalline and thyroid. The occupational doses practiced in intraoral radiology were shown to be adequate, but the individual monitoring program for professionals should be implemented, considering the workload of the attendance rooms.

In Curitiba, $82 \%$ of the evaluated sites use portable chambers of manual revelation. In $72.6 \%$ of cases the revelation is visual, and through the "coin test", it was proven that only $34 \%$ of the revelation boxes seal the entry of light. These results demonstrate that the revelation boxes are widely used in dentistry, but they allow the light to enter on the most part. The entry of light causes veiling of the image and, consequently, loss of diagnostic quality. This factor can cause diagnostic error, repetition of radiographs and, therefore, unnecessary exposure of patients to ionizing radiation. The image processing through the visual method produces images with low diagnostic quality and do not provide the standardization of densities in the radiographic image.

The results showed that the dentists have little knowledge and no interest in the radiation protection recommendations. More supervision and information are clearly needed. Moreover, dentists have vague knowledge about the operation of radiological equipments and the need for periodic maintenance. The lack of information generates failure in the application of procedures, as well as the inappropriate use of individual or collective radiation protection equipments (Santos et al., 2010). Gurgacz and Gewher (2004) implemented a Quality Control Program in dental offices. The study indicated that after lectures and training there was greater awareness and change of procedures used by dentists and auxiliaries regarding radiation protection in dental offices.

\section{References}

Abbott P. Are dental radiographs safe? Australian Dental Journal. 2000; 45(3):208-13. http://dx.doi.org/10.1111/j.1834-7819.2000. tb00559.x. PMid:11062940.

Alcaraz M, Velasco F, Martinez-Beneyto Y, Alcaraz-Saura M, Velasco E, Achel GD, Canteras M. Evolution of diagnostic reference levels in Spanish intraoral radiology. Radiation Protection Dosimetry. 2012; 151(1):166-71. http://dx.doi. org/10.1093/rpd/ncr467. PMid:22267271.

Bonzoumet SPJ. Avaliação da exposição na região dos olhos e do pescoço em pacientes submetidos a exame periapical completo [dissertation]. Rio de Janeiro: Universidade Federal do Rio de Janeiro; 2006.

Brasil. Ministério da Saúde. Secretaria de Vigilância Sanitária. Portaria n ${ }^{\circ} 453$ de 01 de junho de 1998. Diretrizes de proteção radiológica em radiodiagnóstico médico e odontológico. Diário Oficial da República Federativa do Brasil, Brasília, jun. 1998.

Bushong SC. Ciência radiológica para tecnólogos: física, biologia e proteção. 9th ed. Rio de Janeiro: Elsevier; 2010.

Gomes CK, Duque ACR, Dias IM, Martins MEMN, Devito KL. Avaliação do conhecimento dos usuários da Faculdade de odontologia da UFJF quanto às medidas de radioproteção. Odontologia Clínico-Científica. 2012; 11(1):25-9.

Gurgacz MS, Gewher PM. Desenvolvimento e implementação de um programa de garantia de qualidade em consultórios odontológicos. Revista da ABRO. 2004; 5(1):4-8. 
Santos RA, Miranda AC, Silva EC. As normas de radioproteção e o uso de equipamentos de proteção individual na concepção dos cirurgiões-dentistas. Ciencia \& Saude Coletiva. 2010; 15(Suppl 2):3125-7. http://dx.doi.org/10.1590/S141381232010000800016. PMid:21049152.
Tilly JG Jr. Física radiológica. 1st ed. Rio de Janeiro: Guanabara Koogan; 2010.

United Nations Scientific Committee on the Effects of Atomic Radiation - UNSCEAR. Sources and effects of ionizing radiation. New York: United Nations Publication; 2010. v. 1.

\footnotetext{
Authors

Cristiano Miguel $^{1 *}$, Frieda Saicla Barros ${ }^{1}$, Anna Silvia Penteado Setti da Rocha ${ }^{1}$, João Gilberto Tilly Junior ${ }^{2}$, Cláudio Domingues de Almeida ${ }^{3}$

${ }^{1}$ Programa de Pós-graduação em Engenharia Biomédica - PPGEB, Universidade Tecnológica Federal do Paraná UTFPR, Av. Sete de Setembro, 3165, CEP 80230-901, Curitiba, PR, Brazil.

${ }^{2}$ Unidade de Imagem e Radioterapia - UNIR, Hospital de Clínicas, Universidade Federal do Paraná - UFPR, Curitiba, PR, Brazil.

${ }^{3}$ Departamento de Física Médica, Instituto de Radioproteção e Dosimetria - IRD, Rio de Janeiro, RJ, Brazil.
} 